\title{
Determination of Acaricide Resistance in Rhipicephalus (Boophilus) microplus (Acari: Ixodidae) Field Populations of Argentina, South Africa, and Australia With the Larval Tarsal Test
}

\author{
L. LOVIS, ${ }^{1,2,3}$ J. REGGI ${ }^{4}$ M. BERGGOETZ, ${ }^{1}$ B. BETSCHART, ${ }^{1}$ AND H. SAGER ${ }^{2}$
}

\begin{abstract}
J. Med. Entomol. 50(2): 326-335 (2013); DOI: http://dx.doi.org/10.1603/ME12127
ABSTRACT Infestations with ticks have an important economic impact on the cattle industry worldwide and resistance to acaricides has become a widespread phenomenon. To optimize their treatment strategy, farmers need to know if and against which classes potential acaricide-resistance does occur. Bioassays are used to assess the resistance level and pattern of Rhipicephalus (Boophilus) microplus populations. The objective of the current study was to assess the susceptibility of field populations originating from Argentina (8), South Africa (3), and Australia (2) using the Larval Tarsal Test. Nine acaricidal compounds from five major classes were tested: organosphosphates, synthetic pyrethroids (SP), macrocyclic lactones, phenylpyrazols, and amidines. The resistance ratios at concentrations inducing 50 and $90 \%$ mortality were used to detect established and emerging resistance. This study confirmed the newly reported presence of amitraz resistance in populations from Argentina. In addition, resistance to SP appeared to be widespread (88\%) in the Argentinean farms, which had been selected based on the observation of lack of treatment efficacy by farmers. In South Africa one of the three populations was found to be resistant to SP and to a phenylpyrazol compound (pyriprol). Furthermore, resistance to organosphosphates and SP was observed in Australia. Finally, the Larval Tarsal Test proved to be a suitable test to evaluate the susceptibility of $R$. microplus field populations to the most relevant acaricidal classes.
\end{abstract}

RESUMEN Las infestaciones por garrapatas tienen un importante impacto económico en la industria del ganado de todo el mundo y la resistencia a los acaricidas se ha convertido en un fenómeno generalizado. Con el fin de optimizar la estrategia de los tratamientos, los ganaderos necesitan saber en contra de cuáles clases de acaricidas ocurre esa potencial resistencia. Se utilizan bioensayos para evaluar el patrón y nivel de resistencia de Rhipicephalus (Boophilus) microplus. El objetivo del presente estudio fue evaluar la susceptibilidad de poblaciones de campo procedentes de Argentina (8), Sudáfrica (3) y Australia (2) usando la prueba del tarso de las larvas (LTT). Nueve compuestos acaricidas de cinco clases principales: organofosforados (OP), piretroides sintéticos (SP), lactonas macrocíclicas (ML), fenilpirazoles (PYZ) y amidinas. Para detectar resistencia establecida y emergente, se calcularon niveles de resistencia basados en concentraciones que inducen mortalidad a $50 \%$ y $90 \%$. Este estudio confirma la nueva denuncia de la presencia de resistencia al amitraz en las poblaciones de garrapatas de Argentina. Además, la resistencia a SP parece estar muy difundida (88\%) en los establecimientos argentinos, seleccionados sobre la base de la observación de los ganaderos, de la falta de eficacia de los tratamientos. En Sudáfrica, en una de las tres poblaciones, se encontró que era resistente a SP y a un compuesto PYZ (pyriprol). Además, resistencia a OP y SP fue observada en Australia. Finalmente, la LTT ha demostrado ser un ensayo adecuado, para evaluar la susceptibilidad de poblaciones de campo de $R$. microplus a las clases acaricidas más relevantes.

KEY WORDS Larval Tarsal Test, Rhipicephalus (Boophilus) microplus, Acaricide resistance, Argentina

Ticks are the major limiting factor to cattle husbandry in many tropical and sub-tropical areas and cause important economic losses (Graf et al. 2004). Among

\footnotetext{
This article is part of the Ph.D. of Leonore Lovis.

${ }^{1}$ University of Neuchâtel, Institute of Biology, Laboratory of Parasitology, Rue Emile-Argand 11, 2000 Neuchâtel, Switzerland.

${ }^{2}$ Novartis Animal Health Research Center, Chemin de la Petite Glâne, 1566 St-Aubin (FR), Switzerland.

${ }^{3}$ Corresponding author, e-mail: leonore.lovis@unine.ch.

${ }^{4}$ Novartis Animal Health, Ramallo 1851, Ciudad Autónoma de Buenos Aires (C1429DUC), Argentina.
}

them, the southern cattle tick Rhipicephalus (Boophilus) microplus (Canestrini) has developed resistance to all the available classes of acaricides with the exception of the growth regulators and the naturalytes (Kemp et al. 1998, FAO 2004, Castro-Janer et al. 2011). North-Argentina is at the southern limit of its distribution in Latin America, and cattle ticks tend to spread toward south despite the current eradication program (d'Agostino 2010). In 1992, nine million cattle were estimated to be infested with R. microplus ticks (Guglielmone 1992) and total losses were estimated to be 

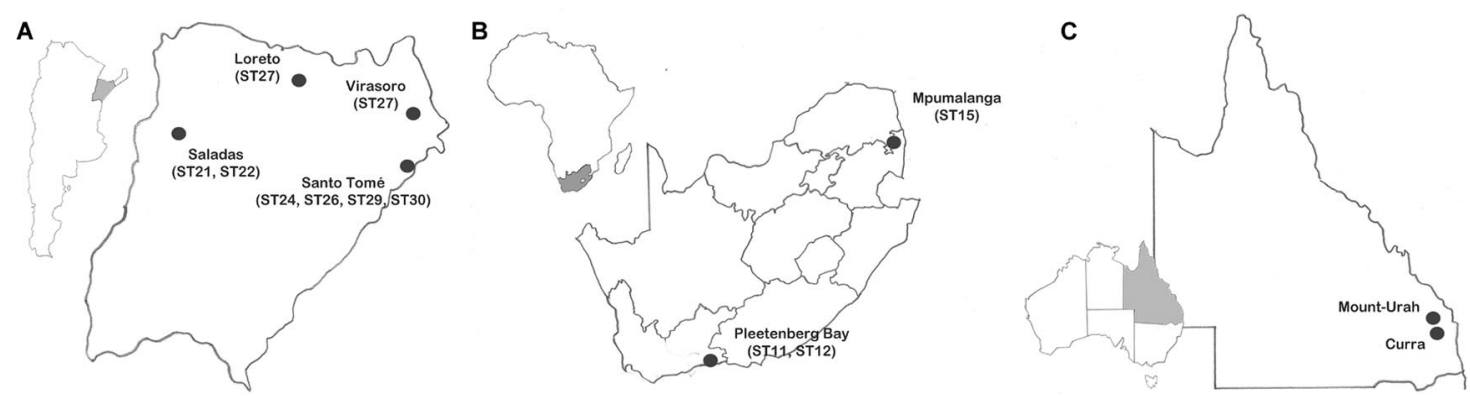

Fig. 1. Locations of the populations collected in (A) Argentina (Province of Corrientes), (B) South Africa (Provinces of Western Cape and Mpumalanga), and (C) Australia (State of Queensland).

over 150 million United States dollars (Späth et al. 1994). However, few reports of acaricide resistance in Argentina are available in the literature. Resistance to organophosphates (OP) was first reported in the 1970s (Grillo Torrado and Gutiérrez 1970, Grillo Torrado and Pérez Arrieta 1977) while synthetic pyrethroid (SP) resistance was first identified in 1996 in Argentina (Caracostantógolo et al. 1996) and then repeatedly reported in the 2000s (Mangold et al. 2004, Guglielmone et al. 2006). The first case of amitraz resistance was very recently described in the province of Corrientes (Cutullé et al. 2013). There is also only little information available on acaricide-resistance of R. microplus in South Africa. Its resistance to OP was first reported in 1979 (Baker et al. 1979). Later, resistance to SP and to amitraz have also been identified in Boophilus spp., firstly without distinction of the species (Kemp et al. 1998, Strydom and Peter 1999, de Bruin 1999) and in 2008 in R. microplus (Ntondini et al. 2008). In Australia, R. microplus was introduced accidentally with imported cattle, probably before 1870 (Angus 1996, Graf et al. 2004) and spread since then to the northern and the eastern part of the country (Cutullé et al. 2009). Acaricide resistance in Australia is well documented. Resistance to OP appeared in the mid-1960s (Shaw and Malcolm 1964, Shaw 1966, Roulston et al. 1968) and was widespread by the mid1970s (Roulston et al. 1981). Resistance to SP appeared in the late 1980s (Nolan et al. 1989) and increased rapidly (Kemp et al. 1998, Jonsson et al. 2000). In comparison, amitraz resistance, which appeared in the early 1980s (Nolan 1981), spread in Australia much more slowly (Kemp et al. 1998, Jonsson et al. 2000, Jonsson and Hope 2007). To our knowledge, no resistance to macrocyclic lactones (ML) or phenylpyrazol (PYZ) compounds has ever been reported in any of these three countries.

Various bioassays are used to evaluate tick susceptibility, such as the adult immersion test (AIT) (FAO 2004), the larval packet test (LPT) (FAO 2004) and the larval immersion test (LIT) (Shaw 1966, Sabatini et al. 2001). More recently a new bioassay, the larval tarsal test (LTT), was developed and compared with the LPT and was shown to be equally sensitive to detect resistance to coumaphos, SP and amitraz (Lovis et al. 2011). The advantage of the LTT is to allow testing a large number of compounds and doses in little time and with a small number of engorged females.

The objective of the current study was to apply the LTT to field populations originating from Argentina, South Africa, and Australia to assess their susceptibility to nine compounds from five major classes (OP, SP, ML, PYZ, and amidines).

\section{Materials and Methods}

Tick Strains. The Muñoz strain was used as the susceptible reference strain. This strain was collected during an outbreak in Zapata County, Texas, in 1999. It was then established and reared without acaricide selection at the Cattle Fever Tick Research Laboratory (CFTRL), Edinburg, TX. Some larvae of the F48 generation were transferred to the Novartis Animal Health Research Center (CRA), St-Aubin, Switzerland in 2010 to establish a colony. Ticks used for the bioassays were from F49 and F50 generations.

Engorged females were collected in Argentina, South Africa, and Australia and were shipped to Switzerland for in vitro testing at CRA. ARGENTINA: In November 2010, eight $R$. microplus samples were collected from seven beef cattle farms of the province of Corrientes, north- east Argentina where farmers were complaining about some lack of treatment efficacy. The samples contained 13-41 engorged females collected from 6 to 15 infested cows and were originating from the following four municipalities: Loreto (ST27), Saladas (ST21, ST22), Santo Tomé (ST24, ST26, ST29, and ST30), and Virasoro (ST25) (Fig. 1A). Ticks from ST21 and ST22 were considered as two separate populations although they were collected on the same farm. The cattle from which the ticks were collected were geographically remote and had been treated with compounds of distinct acaricidal classes. SOUTH AFRICA: In February and April 2010, three samples of 10-40 engorged females of $R$. microplus were obtained from South Africa. R. microplus was morphologically differentiated from Boophilus decoloratus (Koch) at collection using a stereomicroscope (Walker et al. 2003). Two samples were collected from cattle held on communal lands where cattle belong to several owners, as it is common in the local African traditions (Pleetenberg Bay area, Western Cape (ST11) and Eglington, Hluvukani area, Mpumalanga (ST15). The 
third population (ST12) originated from a commercial beef cattle farm located in Pleetenberg Bay, Western Cape (Fig. 1B). Populations originating from South Africa and Argentina were intended to be tested in vitro on arrival in Switzerland without being previously maintained on calves. AUSTRALIA: In February 2009 , engorged females of $R$. microplus were collected in two beef cattle farms from Mount-Urah and Curra municipalities, Queensland, Australia (Fig. 1C) and shipped to the CRA to establish a colony that was maintained without acaricide selection. F3 and F4 generations were used for in vitro testing of the Urah and Curra strain, respectively.

For the shipment, engorged females were placed in glass tubes with meshed lids hold in a soft structure and kept in a polystyrene box containing a piece of cloth soaked with distilled water to ensure sufficient humidity. The polystyrene box was placed in a foamed box protected by a cardboard. On arrival in the CRA, ticks were moved to larger containers and maintained at $28 \pm 1{ }^{\circ} \mathrm{C}$ and $80 \%$ relative humidity ( $\left.\mathrm{RH}\right)$ to complete oviposition. Eggs were used for in vitro testing around a week before hatching (F1 generation). For two strains (ST11 and ST12), the use of perforated Falcon tubes instead of glass tubes negatively impacted the preservation of the eggs laid during shipment. On arrival in the CRA, the remaining healthy eggs were allowed to hatch and larvae were used to infest a calf. The resulting engorged females produced a sufficient number of healthy eggs (F2 generation) for in vitro testing.

Acaricides. Technical grade coumaphos (OP), diazinon (OP), cypermethrin (SP), flumethrin (SP), ivermectin (ML), moxidectin (ML), fipronil (PYZ), pyriprol (PYZ), and amitraz were used in this study. Details on these compounds are available in Lovis et al. (2011). Technical grade compounds were dissolved in dimethyl sulfoxide (DMSO; Fluka, Switzerland) to prepare stock solutions at 20,000 parts per million (ppm).

Larval Tarsal Test (LTT). The LTT was carried out as described previously (Lovis et al. 2011). Briefly, 20 $\mu \mathrm{l}$ of a coating solution containing $100 \%$ ethanol and $0.25 \%$ of olive oil (Sigma-Aldrich, Fluka, Switzerland) was dispensed into each well of flat bottom 96-well plates (NUNC, Catalog No. 260836, Denmark) and ethanol was allowed to evaporate overnight under a fume hood. Then, a top dose of each acaricidal compound was prepared in DMSO from the stock solution and 12 two-fold dilutions were subsequently prepared. A volume of $5 \mu \mathrm{l}$ of each dilution was dispensed on the bottom of the corresponding wells of the microtiter plates, that is, a concentration of $566 \mathrm{ppm}$ corresponded to $100 \mathrm{mg} / \mathrm{m}^{2}$. The upper and lower rows as well as one of the inner rows of the plates always contained $5 \mu \mathrm{l}$ of DMSO only. This set-up allowed testing five compounds per plate and each concentration was tested in triplicates on three separate plates. The inner rows containing only DMSO were used as a control. DMSO was evaporated either by using an $\mathrm{N}_{2}$ sampler concentrator (Techne DB-3 DriBlock, Witec AG, Switzerland) or a centrifugal vac- uum concentrator (SC21017 SpeedVac Plus, ThermoSavant).

Plates were used for testing within $3 \mathrm{~d}$ after preparation. Around 50 eggs were distributed per well using a seed counter (elmor, Switzerland). Plates were incubated for $24 \mathrm{~h}$ at $28 \pm 1^{\circ} \mathrm{C}$ and $\approx 95 \% \mathrm{RH}$ before being sealed with a transparent sealing film (VIEWseal, Greiner bio-one, Switzerland). Sealed plates were then placed at $28 \pm 1{ }^{\circ} \mathrm{C}$ and $70-80 \% \mathrm{RH}$. Plates were removed from the environmental chamber around $2 \mathrm{wk}$ after hatching and larval mortality was evaluated by counting dead or alive larvae using a stereomicroscope. Larval motility and global appearance were used as criteria to assess mortality.

The Argentinean populations were all tested with the nine selected compounds except ST30 that was tested with only one compound of each class because of a limited number of ticks available. The Australian and South African populations were tested with the same nine compounds except diazinon that was not tested. All the compounds were tested at the same concentration range $\left(0.05-100 \mathrm{mg} / \mathrm{m}^{2}\right)$ for the two Australian strains. This range was adapted for the Argentinean and South African populations and the following concentrations were tested: fipronil, flumethrin, pyriprol: $0.003-6.25 \mathrm{mg} / \mathrm{m}^{2}$; moxidectin: $0.05-100 \mathrm{mg} / \mathrm{m}^{2}$; ivermectin: $0.05-100$ or $0.2-400$ $\mathrm{mg} / \mathrm{m}^{2}$; cypermethrin: $0.2-400 \mathrm{mg} / \mathrm{m}^{2}$; amitraz: $0.1-$ 200 or $0.4-800 \mathrm{mg} / \mathrm{m}^{2}$; coumaphos, diazinon: $0.4-$ $800 \mathrm{mg} / \mathrm{m}^{2}$.

Statistical Analysis. Data were entered in Excel software (Microsoft Office 2003) and transferred to Intercooled STATA release 11.0 (StataCorp, College Station, TX). All mortality values were normalized by the mortality of the DMSO control wells using Abbott's formula (Abbott 1987). Outer wells of the microplates with increased mortality because of edge effects in plates were removed. The $\mathrm{R}$ software (version 2.12.0) was used for statistical analysis using the drc package (version 2.0-1), specific for modeling dose-response curves (Ritz and Streibig 2005). Dosemortality data were modeled using a five-parameter log-logistic function (drm command) with the lower and upper limits locked at 0 and 100 , respectively. Doses inducing $50 \%$ mortality $\left(\mathrm{LC}_{50}\right), \mathrm{LC}_{90}$, and $\mathrm{LC}_{99}$ and their $95 \%$ CI were estimated with the ED command using the delta option. Resistance ratios based on the $\mathrm{LC}_{50}$ (RR50) and on the $\mathrm{LC}_{90}$ (RR90) were calculated in reference to the susceptible Muñoz strain using the SI command and the delta interval for their $95 \%$ CI. Resistance ratios were considered significant if their $95 \%$ CI did not include 1 . Three classes based on RR values were created to emphasize the increasing resistance intensity. Populations were considered susceptible to a specific compound when the RR was smaller or equal to 4 , moderately resistant for $4<\mathrm{RR} \leq 10$ and highly resistant for $\mathrm{RR}>10$. Potential discriminating doses (DD) were calculated as $2 \times$ $\mathrm{LC}_{99}$ of the susceptible reference strain (Jonsson et al. 2007). The survival rates of the field strains at the DD were predicted using the PR command. Discriminating doses were not generated for amitraz as the use of 
a single DD is not recommended for this compound (FAO 2004, Jonsson et al. 2007, Lovis et al. 2011).

\section{Results}

Doses inducing 50 and $90 \%$ mortality as well as their 95\% CI are displayed in Tables 1-5. The susceptible Muñoz strain was used as reference for comparison with the field populations and RR50, RR90 as well as their $95 \% \mathrm{CI}$ are also available (Tables 1-5). In addition, Tables 1-4 include the survival rates of the field populations at the DD.

The $95 \%$ CI of $\mathrm{LC}_{90}$ and of RR90 were wider than those calculated for $\mathrm{LC}_{50}$ and RR50. Resistance statuses were, therefore, established based on RR50, and then compared in the discussion to those based on RR90. Some discrepancy was observed between the ability of the two estimates to detect resistance in case of absence of parallelism between the dose-response curves of the field populations and the reference strain as illustrated in Fig. 2 for flumethrin and amitraz.

Resistance Status by Country Based on RR50. In Argentina, one case of moderate resistance to diazinon $($ RR50 $=5.4,4.7-6.1)$ was recorded, while all the populations were susceptible to coumaphos. Resistance to SP was the most common. Cypermethrin resistance was detected in all the populations except one (88\%) with RR50 ranging from $4.2(2.5-5.9)$ to 57.0 (37.5-76.5). In addition, two of these populations also demonstrated resistance to flumethrin based on RR50. Finally, all the Argentinean populations were shown to be susceptible to ML and PYZ, while resistance to amitraz was observed in three of the eight populations (38\%) with RR50 ranging between 9.0 (5.9-12.1) and 32.5 (24.1-40.8). Analysis of the three populations originating from South Africa revealed that two of them (ST11, ST12) were susceptible to all compounds while the third one (ST15) was considered as highly resistant to SP $($ RR50 $=101.5,72.4-$ 130.6) and moderately resistant to pyriprol (RR50 = 9.9, 6.0-13.9). Finally the two Australian populations showed similar resistance profiles to the nine tested compounds, both being moderately resistant to coumaphos and highly resistant to SP while they were susceptible to all other compounds.

Discriminating Doses. Survival rates at the DD of the resistant populations (based on RR50) were all $>10 \%$, ranging from 16.1 to $87.1 \%$. A single exception was observed with ST27 when tested with diazinon (5.2\% survival at DD). Survival rates at the DD of the susceptible populations (based on RR50) were below $10 \%$ with the following five exceptions out of 108 tests: ST30 tested with coumaphos ( $15.2 \%$ survival at DD); ST22, ST25, ST26, and ST27 tested with flumethrin (survival rates between 26.1 and $34.5 \%$ at DD).

\section{Discussion}

The concentrations of the acaricidal compounds that were tested in this study were suitable to calculate $\mathrm{LC}_{50}$ and $\mathrm{LC}_{90}$ of susceptible and resistant populations in $97 \%$ of the tests. The remaining 3\% consisted of :
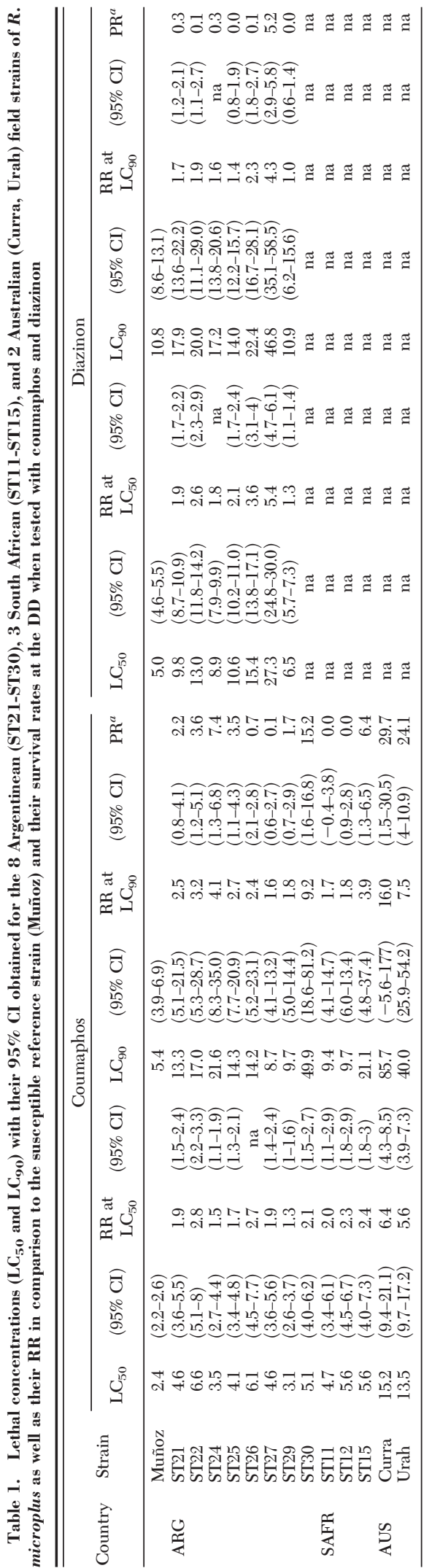


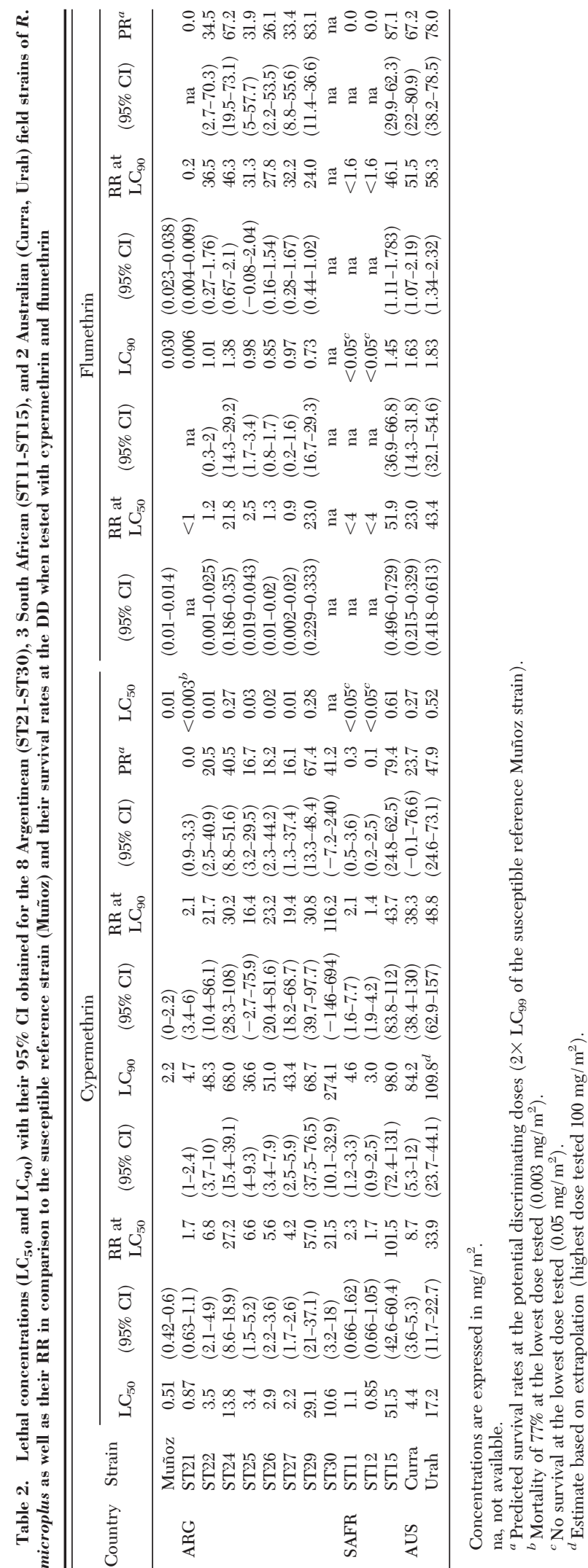



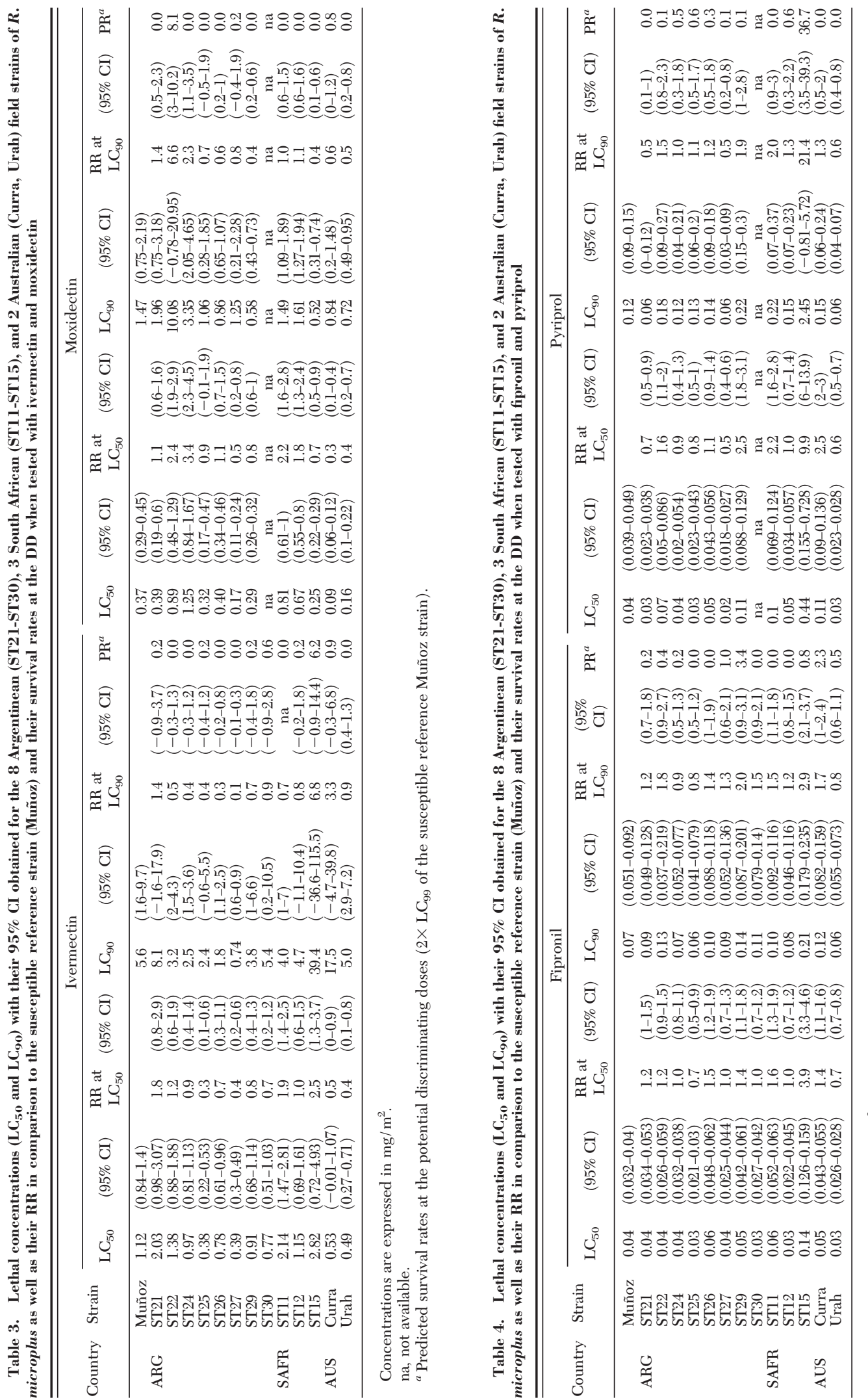
Table 5. Lethal concentrations $\left(\mathrm{LC}_{50}\right.$ and $\left.\mathrm{LC}_{90}\right)$ with their $95 \% \mathrm{CI}$ obtained for the 8 Argentinean (ST21-ST30), 3 South African (ST11-ST15), and 2 Australian (Curra, Urah) field strains of $R$. microplus as well as their RR in comparison to the susceptible reference strain (Muñoz) when tested with amitraz

\begin{tabular}{|c|c|c|c|c|c|c|c|c|c|}
\hline \multirow{2}{*}{ Country } & \multirow{2}{*}{ Strain } & \multicolumn{8}{|c|}{ Amitraz } \\
\hline & & $\mathrm{LC}_{50}$ & $(95 \%$ CI $)$ & $\mathrm{RR}$ at $\mathrm{LC}_{50}$ & $(95 \% \mathrm{CI})$ & $\mathrm{LC}_{90}$ & $(95 \% \mathrm{CI})$ & $\mathrm{RR}$ at $\mathrm{LC}_{90}$ & $(95 \% \mathrm{CI})$ \\
\hline \multirow{9}{*}{ ARG } & Muñoz & 1.1 & $(0.9-1.3)$ & & & 18.5 & $(9-28)$ & & \\
\hline & ST21 & 0.9 & $(0.7-1.1)$ & 0.9 & $(0.7-1.1)$ & 1.9 & $(1.1-2.7)$ & 0.1 & $(0.1-0.1)$ \\
\hline & ST22 & 1.7 & $(1.5-1.9)$ & 1.6 & $(1.2-2)$ & 4.1 & $(3.2-5)$ & 0.2 & $(0.1-0.4)$ \\
\hline & ST24 & 35.4 & $(27.2-43.6)$ & 32.5 & $(24.1-40.8)$ & 79.8 & $(50.3-109.3)$ & 4.3 & $(2-6.6)$ \\
\hline & ST25 & 9.8 & $(7.2-12.3)$ & 9.0 & $(5.9-12.1)$ & 39.0 & $(21.3-56.7)$ & 2.1 & $(0.7-3.6)$ \\
\hline & ST26 & 1.8 & $(1.5-2)$ & 1.6 & $(1.2-2)$ & 7.8 & $(5.1-10.5)$ & 0.4 & $(0.2-0.7)$ \\
\hline & ST27 & 1.0 & $(1-1.1)$ & 1.0 & $(0.6-1.3)$ & 3.9 & $(3.3-4.4)$ & 0.2 & $(0.1-0.4)$ \\
\hline & ST29 & 0.8 & $(0.4-1.1)$ & 0.7 & $(0.5-0.9)$ & 2.6 & $(0.4-4.9)$ & 0.1 & $(0-0.2)$ \\
\hline & ST30 & 22.4 & $(18-26.8)$ & 20.5 & $(15.2-25.8)$ & 42.5 & $(30.2-54.8)$ & 2.3 & $(1.1-3.5)$ \\
\hline \multirow[t]{3}{*}{ SAFR } & ST11 & 1.0 & $(0.8-1.1)$ & 0.9 & $(0.6-1.2)$ & 3.1 & $(2-4.3)$ & 0.2 & $(0-0.3)$ \\
\hline & ST12 & 1.2 & $(0.8-1.6)$ & 1.1 & $(0.9-1.4)$ & 6.9 & $(1-12.9)$ & 0.4 & $(0.1-0.6)$ \\
\hline & ST15 & 3.8 & $(2.7-4.8)$ & 3.5 & $(2.4-4.6)$ & 21.4 & $(6.3-36.6)$ & 1.2 & $(0.2-2.1)$ \\
\hline \multirow[t]{2}{*}{ AUS } & Curra & 1.8 & $(1.1-3.5)$ & 1.6 & $(0.9-2.4)$ & 18.3 & $(8.1-85.8)$ & 1.0 & $(0.3-1.7)$ \\
\hline & Urah & 2.3 & $(1.1-2.5)$ & 2.1 & $(1-3.2)$ & 46.9 & $(9.7-26.8)$ & 2.7 & $(0.1-5.2)$ \\
\hline
\end{tabular}

Concentrations are expressed in $\mathrm{mg} / \mathrm{m}^{2}$.

ST11, ST12, and ST21, for which the tested doses of flumethrin were not sufficiently low to allow determining the $\mathrm{LC}_{50}$ and $\mathrm{LC}_{90}$ and the estimates could not be extrapolated from the model; Urah, for which the $\mathrm{LC}_{90}$ to cypermethrin was slightly above the highest tested dose and the estimate was therefore extrapolated from the model (Table 2).

In general, the RR50 was the method of choice to determine the resistance status because their 95\% CI was smaller compared with RR90. However, RR90 is complementary to RR50 when the dose-response curves of the field populations and the reference strain are not parallel. A smaller slope of the field population, which leads to RR90 greater than RR50, is an indicator that resistance is developing and that the population is heterogeneous, with susceptible and resistant individuals (FAO 2004). Therefore, RR90 has to be considered to detect emerging resistance. In the present survey, the comparison of RR90 and RR50 to distinguish susceptible from resistant field populations reveals that most of the differences would appear for flumethrin. Indeed, because of the smaller slopes of the field populations (Fig. 2a), four of the five Argentinean populations diagnosed susceptible to flumethrin based on RR50 were considered highly resistant based on RR90, with RR90 values between 27.8 (2.2$53.5)$ and 36.5 (2.7-70.3), indicating emerging flumethrin resistance in these populations. Interestingly, these four populations would also have been considered resistant based on their survival rate at the DD. According to the FAO guidelines (FAO 2004) the percentage of ticks surviving at the DD can be taken as the percentage of resistance to the acaricide in the population. Therefore, the interpretation of the results based on the DD corroborates the observation of emerging resistance based on RR90.
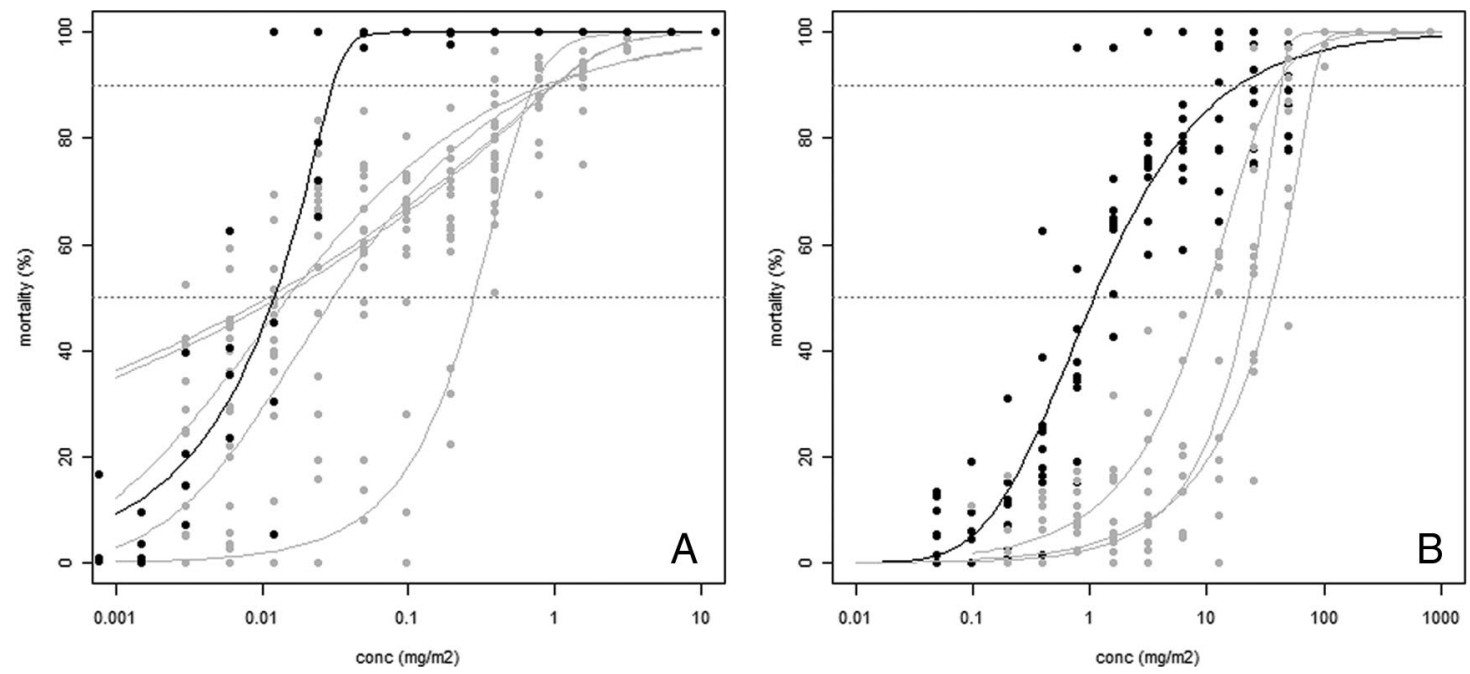

Fig. 2. Dose-response curves of some Argentinean field populations (gray) in comparison to the susceptible reference Muñoz strain (black) (A) ST22, ST25-29 when tested with flumethrin. (B) ST24, ST25, and ST30 when tested with amitraz. The gray dotted horizontal lines indicate 50 and $90 \%$ mortalities. 
Similarly to flumethrin, one population appeared resistant to moxidectin in Argentina when using RR90 $($ ST22, RR90 $=6.6,3.0-10.2)$ and another population appeared resistant to ivermectin in South Africa (ST15, RR90 = 6.8, -0.9-14.4) although the latter case was not significant because of lack of replicates. Even though these last two cases are isolated, because all the other tick populations were susceptible to ML, they should be considered with care. Indeed, RR90 should help detecting emerging resistance and therefore suggest here that ML resistance might be appearing. However, no history of ML-treatment was reported in the farms from which these ticks were collected. Therefore, we are lacking a direct correlation between in vitro-finding and in vivo-situation and to our knowledge no resistance to $M L$ has ever been reported in the literature in Argentina and South Africa.

Conversely, for amitraz, RR90 were much lower than RR50 and two of the three resistant populations based on RR50 would have been considered susceptible based on RR90. Unlike with flumethrin, slopes of the response to amitraz were greater among the resistant populations compared with the reference strain (Fig. 2b). Therefore, amitraz resistance would have been missed considering RR90, indicating that RR90 are inadequate values to identify amitraz resistance.

In Argentina, resistance to SP was detected in seven out of eight populations (88\%), contrasting with the SP resistance average rate of $23 \%$ obtained in populations from 11 Argentinean provinces reported by Guglielmone et al. (2006). Although farms in the current study were selected based on reports of lack of treatment efficacy, it indicates that SP resistance is widespread in Northeast Argentina (Province of Corrientes). The current use of SP for tick-treatments was reported in only three of these farms (ST22, ST29, and ST30). However, an earlier use of this class cannot be excluded in the other farms. In contrast, resistance to $\mathrm{OP}$ was found in a single Argentinean population (ST27). This class of compounds was not reported to be used for treatment by the farmers but OPs have been used in the province before SPs, and lack of efficacy was reported at that time (Grillo Torrado and Gutiérrez 1970). The LTT identified a high resistance to amitraz in ST24 and confirmed the lack of efficacy observed in vivo before tick collection. Resistance to amitraz was also observed in another farm with a history of amitraz treatment (ST25) and in a farm located in the close neighborhood of the above mentioned farm and between which the animals are free to move (ST30, being close to ST24). This survey supports the very recent first report of amitraz resistance in $\mathrm{Ar}$ gentina (Cutullé et al. 2013). Amitraz resistance in Argentina is worrying because this compound currently plays a major role in the eradication program of ticks in this country. In Argentina, tick control is regulated by the SENASA (Animal Health Authorities) through a law (12.566) and a decree (7623/54) that divide the northern part of the country (endemic area) in three areas (SENASA 1938): an infested area, where there is no obligation of eradication; a tick free area, where the percentage of infested fields should not exceed $1 \%$; and between the two, an eradication area, where treatments are compul- sory, aiming to reach eradication. This tick control program has been in progress for $>70 \mathrm{yr}$ and is based on treatments in dipping vats at a 21-d interval (resolution 27/1999) (SENASA 1999). This led to the development of resistance to most of the existing compounds used in dipping vats. Since 1999 injectable (ML) and pour-on (fluazuron) compounds are allowed to be used in combination with plunge dipping or alone (J. Reggi, personal communication). However, amitraz is currently the main active ingredient used for treatment because of the lack of efficacy of the other compounds used for dipping vats, hence the important impact of the development of amitraz resistance.

In South Africa, resistance of Boophilus spp. to OP, SP, and amitraz is well known (Kemp et al. 1998, Strydom and Peter 1999), but ticks were not identified at the species level in these previous studies. A national survey carried out on randomly selected commercial farms showed resistance prevalence of 33, 22, and $7 \%$ to OP, SP, and amidines, respectively (Kemp et al. 1998). In the current study, one sample of ticks was collected from a commercial farm, while the two other samples originated from two herds grouping cattle of different owners and pasturing on communal lands, according to the local African traditions. In these herds the state veterinary authorities offer a weekly amitraz dip, and cattle owners are free to bring their animals for the treatments or to perform any other treatments. Therefore, we do not know exactly to which active ingredients the cattle from which the ticks were collected had been exposed. None of the three populations demonstrated resistance to $\mathrm{OP}$ or amitraz while one population (ST15) demonstrated resistance to SP and pyriprol and a suspicion of ivermectin resistance. The observation of pyriprol resistance, reinforced by a RR50 to fipronil very close to our cut-off value of $4.0($ RR50 $=3.9,3.3-4.6)$ would suggest that some PYZ compounds have been used for treatments; however, pyriprol is not meant to be used for cattle but is exclusively recommended to treat tick infestations in dogs and the probability that these formulations have been used for cattle is very low. However, it cannot be excluded that other products of the PYZ class, such as phytosanitary products, have been used on animals or for plant protection.

In Queensland, Australia, prevalence of resistance to OP was reported to be between 12 and $96 \%$ depending on the regions in 1981 (Roulston et al. 1981). In the same state, prevalence of resistance to flumethrin and to amitraz was estimated to be 76 and $10 \%$, respectively, in 2000 (Jonsson et al. 2000). The two Australian populations analyzed in the present survey also originated from Queensland and demonstrated the two most common resistance in their country, that is, OP and SP resistance, while they were susceptible to amitraz and all the other tested compounds.

Although some authors hypothesized that R. microplus from Australia may be a different species from $R$. microplus from Africa and Latin America (Labruna et al. 2009), this study indicate that acaricidal resistance was comparable between the three selected countries 
and that resistance could be estimated comparing Australian field populations to a Mexican reference strain.

In the current study, the cut-off value of four was selected to distinguish resistant from susceptible ticks based on RR. Lower threshold values have been previously used (Chevillon et al. 2007, Mendes et al. 2007) while in other studies, RR were separated into three classes among which RR of the intermediate class were considered as indicators of tolerance or of incipient resistance (Bianchi et al. 2003, Castro-Janer et al. 2011, Klafke et al. 2012). The cut-off value of four should avoid over-diagnosing resistance. Conversely, one could argue that resistance may be missed. However, if we had selected a threshold value of three instead of four, resistance statuses would have been identical in $96 \%$ of the cases and only four additional cases would have been considered resistant. Therefore, we are confident that this threshold value offers a good compromise to differentiate susceptible from resistant populations.

The use of DD to determine whether resistance is present is widespread with adult tests such as the AIT, but has been criticized (Jonsson et al. 2007). It offers the benefit to reduce the number of engorged females required for testing and the amount of work since a single dose of each compound is tested. Although the benefit of testing a single dose per compound with the LTT is very much reduced, we were interested to see whether the use of DD would be suitable to detect resistance in the current study. A survival rate of ticks at the DD of $10 \%$ was used to differentiate resistant from susceptible tick populations. Resistance statuses based on DD using this cut-off value were in agreement with those based on RR50 or RR90 and the use of DD, therefore, appeared to be adequate to diagnose established and emerging resistance in these field populations.

To conclude, the LTT allowed the detection of resistance in field populations of $R$. microplus ticks originating from Argentina, South Africa, and Australia. Resistance statuses were based on RR50, using a cut-off value of four to differentiate susceptible from resistant populations. In addition, RR90 were also considered to detect emerging resistance. Finally, survival rates at DD were compared with the resistance statuses based on RR50 and RR90. Three cases of amitraz resistance in Argentina were identified as well as the first case of resistance to pyriprol in South Africa. In addition, emerging resistance to ML was suspected in an Argentinean and a South African farm. For this study, ticks were imported to Switzerland for testing. However, in the future, we would like the LTT to be performed in laboratories of the countries of collection. To do so, a detailed description of the test using simplified equipment has been published recently (Lovis et al. 2013).

\section{Acknowledgments}

We thank Peter Rolfe from Novartis Animal Health Australia for providing us with the Australian tick samples, Beatriz d'Agostino from the SENASA, Argentina, for contributing obtaining one of the Argentinean field samples and
Robert Miller from the CFTRL of the U.S. Department of Agriculture for providing us with the susceptible Muñoz strain. We also thank Laure Muller for maintaining the Muñoz strain, ST11 and ST12 at CRA.

\section{References Cited}

Abbott, W. S. 1987. A method of computing the effectiveness of an insecticide. J. Am. Mosq. Control Assoc. 3: 302-303.

Angus, B. M. 1996. The history of the cattle tick Boophilus microplus in Australia and achievements in its control. Int. J. Parasitol. 26: 1341-1355.

Baker, J. A., J. O. Jordaan, and W. D. Robertson. 1979. Ixodicidal resistance in Boophilus microplus (Canestrini) in the Republic of South Africa and Transkei. J. S. Afr. Vet. Assoc. 50: 296-301.

Bianchi, M. W., N. Barré, and S. Messad. 2003. Factors related to cattle infestation level and resistance to acaricides in Boophilus microplus tick populations in New Caledonia. Vet. Parasitol. 112: 75-89.

Caracostantógolo, J., M. E. Muñoz Cobeñas, C. Eddi, R. R. Ambrústolo, G. M. Bulman, and L. Marangunich. 1996. Primera determinación en la República Argentina de una población de Boophilus microplus (Can.) resistente al piretroide sintético alfacipermetrina caracterizada mediante pruebas preliminares. Vet. Arg. 13: 575-582.

Castro-Janer, E., L. Rifran, P. Gonzalez, C. Niell, J. Piaggio, A. Gil, and T. T. Schumaker. 2011. Determination of the susceptibility of Rhipicephalus (Boophilus) microplus (Acari: Ixodidae) to ivermectin and fipronil by Larval Immersion Test (LIT) in Uruguay. Vet. Parasitol. 178: $148-155$.

Chevillon, C., S. Ducornez, T. de Meeus, B. B. Koffi, H. Gaia, J. M. Delathiere, and N. Barré. 2007. Accumulation of acaricide resistance mechanisms in Rhipicephalus (Boophilus) microplus (Acari: Ixodidae) populations from New Caledonia Island. Vet. Parasitol. 147: 276-288.

Cutullé, C., N. N. Jonsson, and J. Seddon. 2009. Population structure of Australian isolates of the cattle tick Rhipicephalus (Boophilus) microplus. Vet Parasitol. 161: 283-291.

Cutullé, C., L. Lovis, B. I. d'Agostino, G. G. Balbiani, G. Morici, D. Citrioni, J. Reggi, and J. L. Caracostantógolo. 2013. In vitro diagnosis of the first case of amitraz resistance in Rhipicephalus microplus in Santo Tomé (Corrientes), Argentina. Vet. Parasitol. 192: 296-300.

d'Agostino, B. 2010. Programa nacional de lucha contra la garrapata común del ganado bovino: Rhipicephalus (Boophilus) microplus, pp. 22-23. In Memorias, XVIII Réunión Científico Técnica, 3-5 November 2010, Mercedes, Corrientes, Argentina.

de Bruin, C. 1999. Acaricides and Boophilus spp. resistance in South Africa, pp. 1. In Abstracts of Papers, 28th Annual Congress of the Parasitological Society of Southern Africa, 20-21 October 1999 Augrabies Falls National Park, South Africa.

FAO. 2004. Resistance management and integrated parasite control in ruminants: guidelines, pp. 25-77. Module 1. Ticks: Acaricide Resistance: Diagnosis, Management and Prevention. FAO, Rome, Italy.

Graf, J. F., R. Gogolewski, N. Leach-Bing, G. A. Sabatini, M. B. Molento, E. L. Bordin, and G. J. Arantes. 2004. Tick control: an industry point of view. Parasitology 129: S427-S442.

Grillo Torrado, J. M., and R. O. Gutiérrez. 1970. Fósfororesistencia de una cepa argentina de garrapata Boophilus microplus. Su medición. Rev. de Med. Vet. 51: 113-125. 
Grillo Torrado, J. M., and A. Pérez Arrieta. 1977. Nuevo tipo de fósforo-resistencia en la garrapata común del ganado bovino (Boophilus microplus) en la República Argentina. Rev. Med. Vet. B. Aires 58: 101-105.

Guglielmone, A. A. 1992. The level of infestation with the vector of cattle babaesiosis in Argentina. Mem. Inst. Oswaldo Cruz 87 (Suppl III): 133-137.

Guglielmone, A. A., A. J. Mangold, M. E. Castelli, V. H. Suarez, D. H. Aguirre, E. Alcaraz, M. M. Cafrune, B. Cetra, O. W. Fader, C. A. Luciani, P. D. Medus, and S. Nava. 2006. Toxicidad in vitro de la cipermetrina para Rhipicephalus (Boophilus) microplus (Can.) y del diazinón para Haematobia irritans (L.) en la Argentina. Rev. Inv. Agropec. 35: 31-41.

Jonsson, N. N., and M. Hope. 2007. Progress in the epidemiology and diagnosis of amitraz resistance in the cattle tick Boophilus microplus. Vet. Parasitol. 146: 193-198.

Jonsson, N. N., D. G. Mayer, and P. E. Green. 2000. Possible risk factors on Queensland dairy farms for acaricide resistance in cattle tick (Boophilus microplus). Vet. Parasitol. 88: 79-92.

Jonsson, N. N., R. J. Miller, and J. L. Robertson. 2007. Critical evaluation of the modified-adult immersion test with discriminating dose bioassay for Boophilus microplus using American and Australian isolates. Vet. Parasitol. 146: 307-315.

Kemp, D. H., R. Thullner, K. R. Gale, A. Nari, and G. A. Sabatini. 1998. Acaricide resistance in the cattle-ticks Boophilus microplus and B. decoloratus: review of resistance data; standardization of resistance tests and recommendation for integrated parasite control to delay resistance. Report of the Animal Health Services, AGAH, FAO. CSIRO Tropical Agriculture, Long Pocket Laboratories, Australia.

Klafke, G. M., E. Castro-Janer, M. C. Mendes, A. Namindome, and T. T. Schumaker. 2012. Applicability of in vitro bioassays for the diagnosis of ivermectin resistance in Rhipicephalus microplus (Acari: Ixodidae). Vet. Parasitol. 184: 212-220.

Labruna, M. B., V. Naranjo, A. J. Mangold, C. Thompson, A. Estrada-Pena, A. A. Guglielmone, F. Jongejan, and F. J. de la. 2009. Allopatric speciation in ticks: genetic and reproductive divergence between geographic strains of Rhipicephalus (Boophilus) microplus. BMC Evol. Biol. 9: 46.

Lovis, L., M. C. Mendes, J. L. Perret, J. R. Martins, J. Bouvier, B. Betschart, and H. Sager. 2013. Use of the Larval Tarsal Test to determine acaricide resistance in Rhipicephalus (Boophilus) microplus Brazilian field populations. Vet. Parasitol. 191: 323-331.

Lovis, L., J. L. Perret, J. Bouvier, J. M. Fellay, R. Kaminsky, B. Betschart, and H. Sager. 2011. A new in vitro test to evaluate the resistance level against acaricides of the cattle tick, Rhipicephalus (Boophilus) microplus. Vet. Parasitol. 182: 269-280.

Mangold, A. J., M. E. Castelli, S. Nava, D. H. Aguirre, and A. A. Guglielmone. 2004. Poblaciones de la garrapata Rhipicephalus (Boophilus) microplus resistentes a los piretroides en Córdoba y Salta, Argentina. Rev. FAVE 3: 55-59.
Mendes, M. C., J. R. Pereira, and A. P. Prado. 2007. Sensitivity of Boophilus microplus (Acari: ixodidae) to pyrethroids and organophosphate in farms in the Vale do Paraíba region, São Paulo, Brazil. Arq. Inst. Biol. 74: 81-85.

Nolan, J. 1981. Current developments in resistance to amidine and pyrethroid tickicides in Australia, pp. 109-114. In G. B. Whitehead and J. D. Gibson (eds.), Proceedings of Tick Biology and Control Conference. Tick Research Unit Rhodes University, Grahamstown, South Africa.

Nolan, J., J. T. Wilson, P. E. Green, and P. E. Bird. 1989. Synthetic pyrethroid resistance in field samples in the cattle tick (Boophilus microplus). Aust. Vet. J. 66: 179-182.

Ntondini, Z., E. M. van Dalen, and I. G. Horak. 2008. The extent of acaricide resistance in 1-, 2- and 3-host ticks on communally grazed cattle in the eastern region of the Eastern Cape Province, South Africa. J. S. Afr. Vet. Assoc. 79: $130-135$.

Ritz, C., and J. C. Streibig. 2005. Bioassay analysis using R. J. Stat. Softw. 12: 1-22.

Roulston, W. J., B. F. Stone, J. T. Wilson, and L. I. White. 1968. Chemical control of an organophosphorus-and carbamate-resistant strain of Boophilus microplus (Can.) from Queensland. Bull. Entomol. Res. 58: 379-392.

Roulston, W. J., R. H. Wharton, J. Nolan, J. D. Kerr, J. T. Wilson, P. G. Thompson, and M. Schotz. 1981. A survey for resistance in cattle ticks to acaricides. Aust. Vet J. 57: 362-371.

Sabatini, G. A., D. H. Kemp, S. Hughes, A. Nari, and J. Hansen. 2001. Tests to determine $\mathrm{LC}_{50}$ and discriminating doses for macrocyclic lactones against the cattle tick, Boophilus microplus. Vet. Parasitol. 95: 53-62.

SENASA. 1938. Servicio Nacional de Sanidad Animal: Ley 12.566. Garrapata. (http://www.senasa.gov.ar/contenido. php?to $=$ n\&in $=981 \&$ ino $=981 \&$ io $=5876)$.

SENASA. 1999. Servicio Nacional de Sanidad Animal: Resolución 27/1999. Garrapata - Plan sanitario. (http://www. senasa.gov.ar $/$ contenido.php?to $=$ n\&in $=1043 \& i o=4588$ ).

Shaw, R. D. 1966. Culture of an organophosphorus-resistant strain of Boophilus microplus (Can.) and an assessment of its resistance spectrum. Bull. Entomol. Res. 56: 389-405.

Shaw, R. D., and H. A. Malcolm. 1964. Resistance of Boophilus microplus to organophosphorus insecticides. Vet. Rec. 76: $210-211$.

Späth, E.J.A., A. A. Guglielmone, A. R. Signorini, and A. J. Mangold. 1994. Estimación de las pérdidas económicas directas producidas por la garrapata Boophilus microplus y las enfermedades asociadas en la Argentina (3a. parte). Therios 23: 454-468.

Strydom, T., and Peter, D. 1999. Acaricidas y resistencia en Boophilus spp en Sudafrica, pp. 35-40. IV Seminario International de Parasitologia Animal Puerto Vallarta, Jalisco, Mexico.

Walker, A. R., A. Bouattour, J. L. Camicas, A. Estrada-Pena, I. G. Horak, A. A. Latif, R. G. Pegram, and P. M. Preston. 2003. Ticks of domestic animals in Africa: a guide to identification of species. Bioscience Reports, Edinburgh, Scotland, United Kingdom.

Received 8 June 2012; accepted 27 November 2012. 